\title{
ASSESSING THE ANTIOXIDANT AND ANTICARCINOGENIC ACTIVITIES OF VIRGIN OLIVE OIL AND PURIFIED OLIVE OIL SAMPLES TREATED WITH LIGHT AND HEAT USING THE AMES TEST
}

\author{
ARASH SHAMS ${ }^{1}$, SEDIGHEH MEHRABIAN² AND SAEED IRIAN2 ${ }^{\star}$ \\ 1Department of Microbiology, Zanjan Branch, Islamic Azad University, Zanjan, Iran. \\ 2Department of Biological Sciences, Tehran Tarbiat Moallem University, Tehran, Iran. \\ ${ }^{*}$ Corresponding Author: Email- irian@tmu.ac.ir
}

Received: January 02, 2012; Accepted: March 01, 2012

\begin{abstract}
Chemical compounds present in fruits and vegetables are involved in combating a number of life-threatening diseases such as cancer, cataract, and cardiovascular and cerebral disorders. Identifying the antimutagenic compounds from plant sources, and evaluating their beneficial properties is an effective step in exalting the human health. Olive oil as a main source of dietary lipids, despite having high levels of unsaturated fatty acids, contains biological compounds such as the phenolic antioxidants with preventative effects against the destructive properties of free radicals and their mutagenic effects on the cellular structures. This study shows the effects of light and temperature on the antioxidant and anticancer properties of purified virgin olive oil using the Ames test. A total of 16 Iranian and Spanish oil samples were used. The antimutagenic activity assay was based on the Ames test and applied the Salmonella typhimurium TA100 mutant line along with the chemical carcinogen sodium azide, while mouse hepatic microsomes were used for the anticarcinogenic assessments. Each assay was performed in triplicates simultaneously, and the percentage of inhibition was determined using the formula (1-T/M) $\times 100$. The highest inhibition percentages with respect to the olive variety were recorded as $63.64 \%, 60.70 \%$ and $46.36 \%$ for oils treated with dark, light, and light + temperature conditions, respectively. Our results indicate that both light and temperature decrease the antioxidant and anticarcinogenic activities of olive oil.
\end{abstract}

Key words- Olive oil, Salmonella typhimurium TA100, Antimutagenic, Anticarcinogenic.

Citation: Arash Shams., et al. (2012) Assessing the antioxidant and anticarcinogenic activities of virgin olive oil and purified olive oil samples treated with light and heat using the Ames test. International Journal of Microbiology Research, ISSN: 0975-5276 (Print) \& EISSN:0975-9174, Volume 4, Issue 2, pp.-173-177.

Copyright: Copyright@2012 Arash Shams., et al. This is an open-access article distributed under the terms of the Creative Commons Attribution License, which permits unrestricted use, distribution, and reproduction in any medium, provided the original author and source are credited.

\section{Introduction}

Using plant compounds as a source of anticancer agents was initially performed by Hartwell in 1967, who used Podophyllotoxin and its derivatives as anticancer agents [1]. With the epidemic and prevalence of cancer in Iran and the rest of the world, the need for medications with minimal side effects and any medication interference, while having a better therapeutic effect has been a subject of research worldwide. To this day, more than $60 \%$ of the anticancer compounds used for treating cancer patients are of plant, aquatic and microorganismal origins [2]. Olive oil with its strong antimutagenic and antioxidative properties has also been described as a valuable nutrient. Olive oil contains phenolic compounds that play important roles in treating diseases including the different kinds of cancer, cardiovascular diseases, blood pressure, rheumatism, alimentary disorders as well as in pain relief and the aging process [3-6]. Today, bacteria are being used for the assessment of antimutagenic activities of different compounds in a short time with excellent results. One of the methods used for assessing the mutation prevention properties of a compound in bacteria is the Ames test. Ames and colleagues assessed the antimutagenic and anticancer activities of different compounds. In this method, Salmonella strains incapable of synthesizing histidine due to mutations are used [7-9].

In a comparative study, it was concluded that systems exploiting Salmonella typhimurium TA100 in the assays are most capable in identifying the mutagenic capacity of different chemicals [10]. This strain carries a specific mutation in its His-operon that makes it histidine auxotroph. This bacterium when in contact with a mutagen will revert and start synthesizing histidine. On the other hand, mouse hepatic homogenate, containing microsomal enzymes 
including cytochrome P450 has anticancer properties. Therefore, in cases where an antioxidant compound shows a synergistic effect with the anticancer activity of cytochrome P450, an anticancer activity can also be assigned to this compound [11-13]. The quality of olive oil depends on numerous factors including light and temperature. These two factors, by affecting the phenolic constituents of olive oil, cause a decrease in its antioxidant properties [14-15]. This research used the Ames test to evaluate the anticancer and antimutagenic properties of light- treated, filtered virgin olive oil.

\section{Materials And Methods Olive oil preparation}

Olive fruits were collected from the Olive Research Station in the city of Tarom (Zanjan, Iran) in late November, 2009 (the best time for harvesting oily olive products in this location).

Samples of ten different olive varieties were collected from the center. In order to prevent any potential microbial contamination and the unwanted biological variations in the fruits, efforts were made to collect fruits manually, preventing any soil contamination. These fruits were then thoroughly washed with water. Oil was extracted using a cold press procedure, and immediately stored in dark bottles. In addition to the aforementioned samples, two oil samples prepared using the traditional method, 1 sample each of factory- made Iranian regular and refined, 2 samples of Iranian factory-made extra-virgin, and 1 sample of Spanish extra-virgin olive oil, all purchased from the local stores to a total of 17 samples used in the experiments.

\section{Bacterial strains}

Salmonella typhimurium strain TA100, directly sent to us by professor Ames, was cultured in a nutrient broth. The overnight culture was used for strain identity confirmation.

\section{Strain TA100 identity assays \\ Rfa mutation}

Sensitivity to viole crystal was tested. A $100 \mu$ l sample of the overnight bacterial culture was inoculated in $2 \mathrm{ml}$ of melted and cooled top agar and spread over an agar nutrient plate. A disk dipped in crystal viole was later placed on this plate and after a 16-hour period, a bright zone was observed around the disk, an indication of the lack of cell growth due to the Rfa mutation.

\section{R-factor assay}

This assay confirms ampicillin resistance. The absence of zone of growth inhibition around the disk was an indication of $a m p^{R}$ and $a$ proof for the presence of the R-factor in the bacterial strain.

\section{UVrB mutation}

This assay confirms UV sensitivity of the strain. A petri dish containing a dense bacterial lawn of TA100 strain was used. One half of the dish was covered with aluminum foil, and the dish was exposed to UV light at a distance of $33 \mathrm{~cm}$ for 8 seconds. Following an 18-hour heating period, the absence of zone of growth inhibition in the UV-exposed half was an indication of UVrB mutation in the strain.

\footnotetext{
Determining the antimutagenic strength of olive oil using Salmonella typhimurium strain TA100

In this assay, the test material (i.e., $0.1 \mathrm{ml}$ of olive oil) is mixed
}

with $0.1 \mathrm{ml}$ of the carcinogen (Sodium azide), present in the positive control, in $3 \mathrm{ml}$ of top agar, $0.1 \mathrm{ml}$ of the overnight culture, and $0.1 \mathrm{ml}$ of histidine and biotin. This mixture was thoroughly spread on a glucose agar plate, and the plate was then overturned and incubated for 24 hours at $37{ }^{\circ} \mathrm{C}$. Each experiment included 3 different plates cultured, simultaneously. Negative control contained $0.5 \mathrm{ml}$ of distilled water instead of sodium azide and shows spontaneous mutation in bacteria, while positive control contains $0.1 \mathrm{ml}$ of the carcinogen. After the heating period, bacterial colonies were counted.

\section{Mouse liver $\mathbf{S 9}$ preparation for carcinogenicity assay}

A broad range of carcinogenic agents require metabolic activation for recognition. In this investigation, 10 male rats, each with an approximate weight of $200( \pm 5)$ grams, provided to us by the Pasteur Institute, were used. Rats were starved for 24 hours in order to get the titer of the liver enzymes to their highest levels. Spinal cords of the animals were then ceased, livers were surgically removed and washed in a $0.15 \mathrm{M}$ Potassium Chloride solution. Livers were cut into pieces using sterile scissors and smashed prior to a 10 min centrifugation at $9000 \mathrm{~g}$. All the above steps were performed at $4{ }^{\circ} \mathrm{C}$. The supernatant (S9) was stored at $-80^{\circ} \mathrm{C}$. The antimutagenic assay was performed in the presence of $\mathrm{S} 9$, as mentioned previously. Positive control included $0.1 \mathrm{ml}$ of the $\mathrm{O} / \mathrm{N}$ culture, $0.1 \mathrm{ml}$ of the mutagen and $0.1 \mathrm{ml}$ of $\mathrm{S} 9$, while the test petri dish contained $0.1 \mathrm{ml}$ of the $\mathrm{O} / \mathrm{N}$ culture, $0.1 \mathrm{ml}$ of the mutagen, $0.1 \mathrm{ml}$ of olive oil and $0.1 \mathrm{ml}$ of $\mathrm{S} 9$. The negative control contained

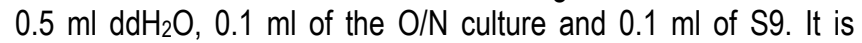
worth mentioning that histidine and biotin were added to all the above petri dishes and that each experiment was performed in triplicates, simultaneously. Bacterial colonies were counted following the heating cycle $[9,11]$.

\section{Calculation of inhibition percentages}

Inhibition percentages were calculated using the Ong and colleagues' formula (1-T/M) x 100, in which T represents the number of revertants in each plate in the presence of the antimutagen, while $T$ stands for the number of revertants in each of the positive control plates [16]. It needs to be mentioned that the number of revertants in the negative control is subtracted from the values of $\mathrm{T}$ (the numerator) and $\mathrm{M}$ (the denominator). Inhibition of $>40 \%$ and $25-40 \%$ are indicative of a strong and a medium antimutagenic effect, respectively, while $a<25 \%$ inhibition indicates the $a b$ sence of this effect [9].

\section{Statistical analyses}

Data such as the number of revertants in the mutagenecity assay were analyzed using the one-way analysis of variance (ANOVA) test in SPSS.

\section{Results}

In accordance with the Salmonella typhimurium TA100 strain genotype, the reduction in the mutant strain of lipopolysaccharides allowed viole crystal penetration, bacterial death and formation of a zone of about $14 \mathrm{~mm}$, while no such zone was formed in the wild type strain. The experimental strain was ampicillin-resistant due to the presence of the R-factor plasmid. UvrB mutation was confirmed by the lack of growth in the irradiated section (Table 1). 
Table 1- Salmonella typhimurium TA100 strain genotype.

\begin{tabular}{llll} 
Experimental strain & rfa mutation & $\begin{array}{l}\text { UvrB } \\
\text { mutation }\end{array}$ & R-factor plasmid \\
Salmonella typhimurium TA100 & + & + & + \\
\hline
\end{tabular}

\section{Antimutagenic effect of olive oil kept in dark conditions}

Oil samples were kept in dark glass bottles in a dark environment. Each experiment was performed in triplicates, simultaneously. Sodium azide was used as the mutagen in the positive controls, and the number of revertants in the presence and absence of S9 were approximately 2600 colonies. A reduction in the number of revertants to 210 in the negative control was a confirmation of the antimutagenic effect of sodium azide. A significant difference $(p \leq$ 0.05 ) was observed among the different olive oils of which, samples 1,2 and 5 had a strong (60\%) antimutagenic and anticarcinogenic effect. This value was further increased in the presence of S9. A medium antimutagenic and a medium anticarcinogenic effects were assigned to samples 3, 4, 6, 7, 8, 9, 10, 13, 14 and 15. Once again, $\$ 9$ addition caused a slight increase in this effect. No antimutagenic effect was observed in the oil samples 11, 12, 16 and 17 (Table 2).

Table 2- Percentages of inhibition in the presence and absence of S9 in dark conditions.

\begin{tabular}{|c|c|c|c|c|}
\hline \multirow{2}{*}{$\begin{array}{l}\text { Number of } \\
\text { revertant } \\
\text { colonies } \\
\text { Samples }\end{array}$} & \multicolumn{2}{|c|}{$\begin{array}{c}\text { Number of Colonies in the } \\
\text { presence of } \$ 9\end{array}$} & \multicolumn{2}{|c|}{$\begin{array}{c}\text { Number of Colonies in the } \\
\text { absence of } 59\end{array}$} \\
\hline & $\begin{array}{l}\text { Average and } \\
\text { deviation }\end{array}$ & $\begin{array}{c}\text { Average of } \\
\text { percentage of } \\
\text { inhibition }\end{array}$ & $\begin{array}{l}\text { Average and } \\
\text { deviation }\end{array}$ & $\begin{array}{l}\text { Average of } \\
\text { percentage of } \\
\text { inhibition }\end{array}$ \\
\hline +Control & $\begin{array}{c}2636.33 \pm 854.1 \\
0\end{array}$ & & $\begin{array}{c}2664.33 \pm 1050 \\
98\end{array}$ & \\
\hline -Control & $210.67 \pm 78.51$ & & $235.67 \pm 52.51$ & \\
\hline Sample 1 & $1021.33 \pm 20.95$ & 61.26 & $1043.33 \pm 19.87$ & 60.84 \\
\hline Sample 2 & $958.67 \pm 69.50$ & 63.64 & $1022.33 \pm 21.23$ & 61.63 \\
\hline Sample 3 & $1335.33 \pm 28.19$ & 49.35 & $1374.67 \pm 32.27$ & 48.4 \\
\hline Sample 4 & $1590.67 \pm 22.05$ & 39.66 & $1496.67 \pm 21.64$ & 43.83 \\
\hline Sample 5 & $1030.33 \pm 12.66$ & 60.92 & $1084.67 \pm 26.04$ & 59.29 \\
\hline Sample 6 & $1474.67 \pm 13.10$ & 44.06 & $1497.33 \pm 24.14$ & 43.8 \\
\hline Sample 7 & $1339.33 \pm 32.36$ & 49.2 & $1362.67 \pm 18.91$ & 48.86 \\
\hline Sample 8 & $1625.00 \pm 33.18$ & 38.36 & $1650.00 \pm 30.51$ & 38.07 \\
\hline Sample 9 & $1828.67 \pm 27.05$ & 30.64 & $1852.33 \pm 20.04$ & 30.48 \\
\hline Sample 10 & $1721.33 \pm 26.23$ & 34.71 & $1745.33 \pm 36.23$ & 34.49 \\
\hline Sample 11 & $2169.00 \pm 24.54$ & 17.73 & $2246.67 \pm 60.30$ & 15.68 \\
\hline Sample 12 & $2036.33 \pm 17.56$ & 22.76 & $2063.33 \pm 19.60$ & 22.56 \\
\hline Sample 13 & $1524.00 \pm 23.55$ & 42.19 & $1552.00 \pm 21.65$ & 41.75 \\
\hline Sample 14 & $1659.33 \pm 24.09$ & 37.06 & $1681.00 \pm 25.96$ & 36.91 \\
\hline Sample 15 & $1509.67 \pm 25.17$ & 42.74 & $1546.67 \pm 41.65$ & 41.95 \\
\hline Sample 16 & $2012.00 \pm 8.64$ & 23.68 & $2003.00 \pm 7.87$ & 24.82 \\
\hline Sample 17 & $2033.67 \pm 10.53$ & 22.86 & $2052.33 \pm 14.34$ & 22.97 \\
\hline
\end{tabular}

\section{Effect of light on the antimutagenecity of olive oil}

At this stage, oil samples $11,12,16$ and 17 with no antimutagenic effect were not included. Oil samples 1, 2 and 5 had the highest rate of inhibition, but showed a lower antimutagenic effect, when compared to the same samples kept in dark. At this stage, a significant difference $(p \leq 0.05)$ was also observed among the different oil varieties.

Samples 3, 4, 6, 7, 8, 9, 10, 13, 14 and 15 showed a medium antimutagenic effect (Table 3 ).

\section{Combinatorial effect of light and temperature on the antimu-} tagenecity of olive oil

At this stage, the first 5 samples with the highest antimutagenic effect were tested. A significant difference ( $p \leq 0.00 .05)$ was evident with a $13 \%$ decrease in inhibition (i.e., $60 \%$ to $47 \%$ ) from dark to light and temperature condition with respect to the first sample, which is an indication of a strong effect of light and temperature on the antimutagenic effect of olive oil (Table 3 ).

Table 3- Comparison of the average and standard deviation from the environmental effects on the antimutagenecity of olive oil.

\begin{tabular}{|c|c|c|c|c|c|c|}
\hline $\begin{array}{l}\text { Expt. } \\
\text { sample }\end{array}$ & SS & k & S9+light & S9-light & $\begin{array}{l}\text { S9+light } \\
\text { and tem- } \\
\text { perature }\end{array}$ & $\begin{array}{l}\text { S9-light } \\
\text { and tem- } \\
\text { perature }\end{array}$ \\
\hline \multirow{3}{*}{1} & 1021 & $=19$ & 112 & & $7 \pm 16$ & 13 \\
\hline & 20.95 & .87 & .04 & .3 & .6 & 6 \\
\hline & $958.67 \pm 6$ & s $1022.33 \pm 21$ & $1036.00 \pm 8$ & $1053.00 \pm 14$ & $1414.00 \pm 16$ & 1429 \\
\hline & 9.5 & .2 & 60 & .72 & 0 & 3 \\
\hline \multirow[t]{2}{*}{3} & $1335.33 \pm$ & $=1374$ & ? $1348.33 \pm 22$ & 1369 & $7 \pm 20$ & $1619.33 \pm 24$ \\
\hline & 28. & .27 & .65 & & & \\
\hline & $1590.67 \pm$ & $1496.67 \pm 2$ & $1618.67 \pm 22$ & $1634.00 \pm 14$ & $1683.33 \pm 9$ & $1695.67 \pm 1$ \\
\hline & 22.05 & & & .97 & & \\
\hline & $1030.33 \pm$ & $1084.67 \pm 26$ & $1045.67 \pm 10$ & $1058.67 \pm 9$ & $1256.33 \pm 13$ & $1263.33 \pm 13$ \\
\hline & 12.6 & .04 & & 98 & & \\
\hline
\end{tabular}

\section{Discussion}

Cancer is considered as one of the main causes of mortality throughout the industrial world in the present century. To this date, a wide range of chemical mutagens and carcinogens have been identified. Scientists believe that damage to the genetic material, changes in DNA sequence and continuity, mutation in genes and other genetic changes in chromosomal structures play important roles in carcinogenesis. The Ames test is a common methodology for screening and identifying both mutagens and antimutagens. In this method, using mutant strains of Salmonella typhimurium, a number of plant-derived compounds have been introduced as both antimutagens and anticarcinogens [12].

\section{Keeping olive oil in a dark environment}

Our results on the antimutagenecity and anticarcinogenicity effects of different olive oil varieties with respect to the positive control (sodium azide) indicated a strong antimutagenic and anticarcinogenic effects for the olive oils 1,2 and 5. These effects are further enhanced in the presence of S9. The reason for a high average of percentage of inhibition in these 3 oils can be attributed to the type of variety [17].

These results are consistent with those of others, investigating the relationship between the Mediterranean diet and cancer, which introduced olive oil as an Anticarcinogen [18]. Oils 3, 4, 6, 7, 8, 9, $10,13,14$ and 15 showed a lower rate of antimutagenecity than the above 3 samples. Once again, this rate is slightly increased following the addition of S9. These results indicate that inclusion of olive oil in a diet can be an effective way in preventing cancer [19]. Oils 11, 12, 16 and17 with no antimutagenic effect demonstrate very little antioxidative activity. These results are consistent with those of others [17] in which, using HPLC analysis, they showed very little phenolic and tocopherol content in several commercial Iranian olive oil samples. The low inhibition percentages of the latter 4 samples can also be due to the duration and the high temperature of the malaxing stage, the method of extraction, and 
the olive variety $(17,20,21,22,23,24,25,26]$. This investigation also used the mouse liver homogenate (S9). The antimutagenecity of olive oil was increased by inclusion of the microsomes, which is indicative of its anticarcinogenicity. This is because in the presence of antioxidants and antimutagens, cytochrome P450 enhances this effect, and hence the oil samples are called anticarcinogens [12]. Our results on the antimutagenic and anticarcinogenic effects of olive oil are consistent with those of the following: A review on the molecular mechanisms of the effects of dietary lipids, including olive oil, on cancer concluded that phenolics and MUFAs (monounsaturated fatty acids) in olive oil are responsible for lowering the incidence of cancer [27]. Using mutant heterozygote Drosophila, a strong antimutagenic effect of olive oil was demonstrated [28]. It has been shown that $n-6$ PUFAs (polyunsaturated fatty acids) are more amenable to peroxidation and conversion to aldehyde products, while MUFAs by scavenging free radicals and a lower tendency to interact with oxygen, play an important role in reducing DNA damage [29]. The latter work also highlighted the valuable and beneficial effects of olive oil on certain cancer types including breast, prostate, colon, urinary tract, bladder, stomach and long cancers, and demonstrated that phenolics in olive oil are important in scavenging DNA damaging reactive oxygen species (ROS). A role for olive oil in lowering cancer risk has been confirmed by others [30]. Lowering the risk of breast and pancreatic cancers, and the protection against tumors have been attributed to a combination of squalene and olive oil [31]. A study reported on the effect of olive oil on colon cancer and identified antioxidants and phenolics as well as the MUFAs as important reducing agents in the incidence of colon cancer [26]. In 1999, Mettlin pointed out the lowering effect of olive oil on the incidence of breast cancer [32].

\section{Effects of light on olive oil}

By assessing the results and the average percentages of inhibition obtained for sunlight-treated samples, It became evident that the rate of inhibition in the light $(57.49 \%)$ is lower than this rate in a dark environment (61.26\%). This lowering effect can be attributed to the destructive property of UV radiation on the phenolic constituents $[33,34,35]$. These findings are in line with those reporting on the effects of different parameters including the packaging material headspace, oxygen, light, temperature and storage time on quality characteristics of virgin olive oil, where they identified a damaging effect of UV light on the antioxidant property and the subsequent quality of olive oil [35]. A study on the effect of temperature and UV on lowering the levels of free $\alpha$ - tocopherol, a - tocopherol dissolved in methanol and a- tocopherol dissolved in hexane, identified UV with a more destructive property on dissolved a-tocopherol levels. By generating monoxy and hydrogen peroxide free radicals and converting tocopherol to oxiradicals, ultraviolet light causes the destruction of the vitamin [36]. Present study is also showing the destructive effect of light on antimutagenic and anticarcinogenic properties of olive oil. A study on the effect of light on the oxidative resistance of date oil showed that UV light by expediting the oxidation of the oil resulted in higher peroxide levels and eventually a lower oil quality [3]. Our results are in line with those of some Italian researchers stating that, storage of olive oil in transparent glass bottles and its exposure to sun light would result in a significant reduction in its potential antioxidative property and nutritional value [37].

\section{Combinatorial effects of light and temperature on olive oil}

Our results on olive oil samples exposed to both light and temperature indicated a significant drop in the average percentage of inhibition $(47.36 \%)$. This finding can be justified by the hydrolytic effect of temperature on long chain fatty acids resulting in the production of peroxides and eventually a reduction in the antioxidative and anticarcinogenic properties of olive oil $[3,14,35,38$ 41]. A report which assessed the effects of temperature and type of food simulant on antioxidant stability and found that high temperatures lead to the instability of antioxidants in a molecular waydependent manner. They found low MW phenolics such as DBP, $\mathrm{BHT}$ and BHA being more stable, while the stability of medium MW phenolics including AO 2246 and AO 425 was a function of temperature, and finally the high MW phenolics and antioxidants were quite unstable even at lower temperatures [42]. Effect of temperature and UV light on the degradation of a- tocopherol in free and dissolved forms (methanol and hexane) has been reported by others [36], where a destructive effect on MUFAs and antioxidants of olive oil was determined. A study showed that temperatures higher than $180{ }^{\circ} \mathrm{C}$ significantly reduce the antioxidant defense potential (AOP), while elevating the MDA (malondialdehyde) levels resulting in peroxide formation and probably enhanced disease processes [43]. Finally, applying a preliminary approach to productive modeling of extra virgin olive oil stability it has been shown that UV light exposure and high temperature lead to oil decay and instability, and eventually to a lower shelf- life [41].

\section{References}

[1] Hartwell J.L. (1967) Plants used against cancer., 71, 30-34.

[2] Srivastava V., Negi A.S., Kuma J.K., Gupta M.M. and Khanuja S.P.S. (2005) Bioorganic \& Medicinal Chemistry, 13(21), 5892 $-5908$.

[3] Ghazali Z., Wan Nik W.B., Ku Bulat K.H., Ani F.N. and Xian L.F. (2006) 1st International Conference on Natural Resources Engineering \& Technology, 631-637.

[4] Hrncirik K. and Fritsche S. (2004) Eur. J. Lipid Sci. Technol., 106, 540-549.

[5] Møller P., Wallin H. and Knudsen L.E. (1996) Chem. Biol. Interact., 102(1), 1-36.

[6] Vitaglione P. and Fogliano V. (2004) J. Chromatogr. B. Analyt. Technol. Biomed. Life Sci., 802(1), 189-199.

[7] Ames B.N., Mccan J. and Yamasaki E. (1975) Mutational Resarch., 31(6), 247-264.

[8] Brooks G. and Noroozi J. (2002) Intestinal Gram negative bacteria in microbiology.

[9] Mehrabian S., Majd A. and Dana R. (2009) plantogo major L. in vegetative and generative stages in Hessarak-Karaj and Langrood areas. Quarterly periodicals, 1(2), 23-32.

[10]Zeiger E., Shloy J.A. and Bakaleetal G. (1996) Salmonella mutagenicity. J. Mutagenesis, 11.

[11]Bentley K.W. (2000) J. Royal Society of Chemistry, 10, 247265.

[12]Rosenkranz H.S. (2003) Mutation Research/Fundamental and Molecular Mechanisms of Mutagenesis, 529(1-2), 117-127. 
[13]Sato F., Hashimoto T., Hachiya A., Tamura K.I., Choi K.B., Morishige T., Fujimoto H. and Yamada Y. (2001) Metabolic engineering of plant alkaloid biosynthesis, 98(1), 367-372.

[14] Parvaneh V. (1998) Quality control and chemical analysis of nutrients.

[15]Ravaghi M., Haddad khoda parast M.H. (2005) First special conference on olive oil.

[16][16] Ong T.M., Whong W.Z., Stewart J. and Brockman H.E. (1986) Mutation Research, 173(2), 111-5.

[17]Fahim danesh M., Ghavami M., Hamsi A.H. (2008) Quarterly periodicals of Science and Food industry, 5, 3.

[18]Colomer R. and Menéndez J.A. (2006) Clin. Transl. 8(1), 1521.

[19]Owen R.W., Haubner R., Würtele G., Hull E., Spiegelhalder B. and Bartsch H. (2004) Eur. J. Cancer Prev., 13(4), 319-326.

[20]Gómez-Alonso S., Fregapane G., Salvador M.D. and Gordon M.H. (2003) J. Agric. Food Chem, 51(3), 667-672.

[21]Tena N., Aparicio R. and García-González D.L. (2009) J. Agric. Food Chem, 57(21), 9997-10003.

[22]Evangelista C.M.W., Antunes L.M.G. and Bianchi M.L.P. (2006) Genetics and Molecular Biology, 29, 730-734.

[23]Burgos-Hernandez A., Peña-Sarmiento M. and MorenoOchoa F. (2002) Food Chem, 40(10), 1469-1474.

[24]Isidori M. and Parrella A. (2009) Food Science and Technology International, 15(3), 267-273.

[25]Psomiadou E. and Tsimidou M. (1999) J. Agric. Food Chem, 47, 4025-4032.

[26]Stoneham M., Goldacre M., Seagroatt V. and Gill L. (2000) J. Epidemiol. Community Health, 54, 756-760.

[27]Escrich E., Moral R., Grau L., Costa I. and Solanas M. (2007) Mol. Nutr. Food Res, 51(10), 1279-1292.

[28]Campos-Sanchez J., El Hamss R., Munoz-Serrano A., Analla M. and Alonso-Moraga A. (2006) Antigenotoxicity studies of olive oils. I Congreso De Cultura Del Olivo, 783-795.

[29]López S., Bermúdez B., Pacheco Y.M., Abia R., Muriana F.J.G. (2004) Olive oil and cancer. Grasas y Aceites, 55, 3341.

[30]Martin-Moreno J.M. (2000) J. Epidemiol. Commun. Health, 54, 726-727.

[31]Newmark H.L. (1997) Cancer Epidemiology, Biomarkers \& Preventio, 6, 1101-1103.

[32]Mettlin C. (1999) CA Cancer J. Clin, 49, 138-144.

[33]Kiritsakis A.K., Nanos G.D., Polymenopoulos N., Thomai T. and Sfakiotakis E.M. (1998) J. Amer. Oil Chem. Soc., 75, 721724.

[34]Lamuela-Raventós Rosa M., Gimeno E., Fitó M., Castellote A.I., Covas M., Torre-Boronat M.C. and Lopez- sabater M.C. (2004) Biol. Res., 37, 247-252.

[35]Pristouri G., Badeka A. and Kontominas M.G. (2010) Food Control, 21(4), 412-418.

[36]Sabliov C.M., Fronczek C., Astete C.E., Khachaturyan M., Khachatryan L. and Leonardi C. (2009) J. Am. Oil Chem. Soc., 86, 895-902.

[37]Ranjzad J. (2008) Food and Drug, Tabriz Medical Science University. Mianeh Health and Therapy Network.

[38]Ramirez-Tortosa M.C., Urbano G., López-Jurado M., Nestares T., Gomez M.C., Mir A., Ros E., Mataix J. and Gil A. (1999) J. Nutr., 129, 2177-2183.
[39]Sillani J. (2002) J. Clin. Nutr, 11, 79-84.

[40]Tena N., Garc a-Gonz lez D.L. and Aparicio R.N. (2009) J. Agric. and Food Chem., 57(22), 10505-10511.

[41]Zanoni B. and Bertuccioli M. (2005) Journal of the Science of Food and Agriculture, 85, 1492-1498.

[42]Dopico-Garcia M.S., López-Vilariño J.M. and GonzálezRodríguez M.V. (2006) Journal of Applied Polymer Science, 100(1), 656-663.

[43]Durak I., Yalcin S., Kacmaz M., Cimen M.Y.B., Buyukkocak S., Avci A. and Ozturk H.S. (1999) Journal of Toxicology and Environmental Health, Part A 57, 585-589. 